\title{
On the importance of cumulus penetration on the microphysical and optical properties of stratocumulus clouds
}

\author{
S. Ghosh ${ }^{1}$, S. Osborne ${ }^{2}$, and M. H. Smith ${ }^{1}$ \\ ${ }^{1}$ Institute for Atmospheric Science, School of the Environment, University of Leeds, Leeds, LS2 9JT, UK \\ ${ }^{2}$ Met Office, Exeter, Devon, EX1 3PB, UK
}

Received: 10 June 2004 - Published in Atmos. Chem. Phys. Discuss.: 20 August 2004

Revised: 14 February 2005 - Accepted: 2 March 2005 - Published: 7 March 2005

\begin{abstract}
Owing to their extensive spatial coverage, stratocumulus clouds play a crucial role in the radiation budget of the earth. Climate models need an accurate characterisation of stratocumulus in order to provide an accurate forecast. However, remote sensing as well as in-situ observations reveal that on several occasions, cumulus clouds present below the stratocumulus, often have a significant impact on the main stratocumulus microphysical properties. This was observed during the ACE-2 (Aerosol Characterisation Experiment-2) campaign designed to study the impact of polluted continental air on stratocumulus formation. In this paper we used a detailed micro-physical chemical parcel model to quantify the extent of this cumulus-stratocumuls coupling. In addition, we made extensive use of microphysical observations from the C-130 aircraft that was operated during ACE-2. For the ACE-2 case studies considered in this paper, our analysis revealed that the chemical, microphysical and optical characteristics of the main stratocumulus cloud deck had significant contributions from cumulus clouds that often penetrated the stratocumulus deck. The amount of fine mode ionic species, the average droplet number concentrations, the effective radii and the optical depths during the flight A562 (when cumulus clouds interacted with the main stratocumulus) were estimated and model runs that included this effect yielded microphysical and optical properties which compared more favourably with the observations than the runs which did not. This study highlights the importance of including these cumulus effects in stratocumulus related modelling studies.
\end{abstract}

Correspondence to: S. Ghosh

(sat@env.leeds.ac.uk)

\section{Introduction}

The evolution of droplet spectra within stratocumulus clouds can be greatly influenced by cumulus clouds which often are observed to grow into the bases of the stratocumulus layers from a lower level. This situation was encountered during ASTEX (Atlantic Stratocumulus Transition Experiment) (Martin et al., 1995) where aircraft observations show significant modification of the droplet spectrum associated with cumulus penetration. These authors conclude from satellite observations and measurements that the interaction of cumulus clouds and stratocumulus layers has a modifying effect on the reflectivity of stratocumulus especially in the sub-tropics and in the late afternoon in mid-latitudes. The Martin et al. (1994) results also point to the possibility of drizzle formation due to cumulus penetration - although the mechanisms were not clarified. They found that the effect is most noticeable when the droplet concentration in the stratocumulus is large. The mixing, under saturated conditions, of droplet spectra grown by condensation under very different conditions in the cumulus and stratocumulus gives rise to a broad spectrum which favours subsequent growth by coalescence (Jonas, 1996).

Although the process of cumulus formation below a stratocumulus cloud has also been observed during the more recent ACE-2 (Aerosol Characterisation Experiment-2) campaign, no systematic study has been undertaken to explore this cumulus-stratocumulus interaction. In this paper, we have examined how cumulus clouds present below a stratocumulus deck affect the microphysical and optical properties of the main cloud, by using a detailed microphysical chemical parcel model as well as observational data. One of the aims of the ACE- 2 experiment was to understand how polluted continental air masses affect the microphysical development of stratocumulus clouds and also to understand how pollutant gases and contaminated aerosols modulate cloud microphysical properties. We chose to concentrate on

(C) 2005 Author(s). This work is licensed under a Creative Commons License. 
19 July 1997 (flight A562) as part of the Lagrangian experiments conducted during ACE-2 (see Johnson et al. (2000) for an overview of ACE-2) because, on this day, the stratocumulus cloud was contaminated with polluted air masses advected from Europe and, in addition, cumulus clouds were seen below the base of the stratocumulus. On several occasions (up to $10 \%$ of all cases), these cumulus clouds penetrated the stratocumulus base. As a result, the aerosol particles within the cumulus had an opportunity to interact with the stratocumulus. The resultant chemical and microphysical evolution of the stratocumulus cloud was thus much perturbed by the cumulus cloud modulating it from below. The aerosol particles within the cumulus cloud were subjected to different dynamical influences as compared to the stratocumulus above. The use of a detailed microphysical parcel model enabled us to study the chemical processing, droplet spectral evolution, and the optical properties of this cumulus-stratocumulus interaction through numerical experiments which could separate out the microphysical and chemical processing of aerosol and cloud droplets grown within the cumulus and the stratocumulus regimes. Finally, observations showed that the main stratocumulus deck was characterised by some measure of horizontal inhomogeneity. In order to ascertain whether horizontal variations, over the significant length span covered by the aircraft, also showed significant variabilities in the optical properties, we conducted some further sensitivity tests. We chose a polluted day without any drizzle (18 July, flight A560) to ensure that the aircraft flight path sampled an extended region of unbroken cloud. In addition, on 18 July a significant variability in the observed cloud droplet number concentrations $\left(N_{d}\right)$ was noticed over the sampled horizontal flight path, although no cumulus clouds were observed on that day.

The layout of the paper is as follows. First, we present the case study overview for the two polluted days along with details of the aircraft observations. Then we include a brief description of the model, followed by a discussion on how the model results compare with observations including chemical processing, with and without cumulus dynamics. This is followed by a discussion on the optical properties and also their horizontal variability. Finally, the droplet spectra are compared with observations.

\section{Case study overview}

2.1 Air craft measurements - data sets and instrumentations

ACE-2 was undertaken during June and July 1997 in the subtropics near the North Atlantic region of the Canary Islands in order to study the regional radiative forcing of different aerosol types (Raes et al., 2000). The aims of ACE-2 included quantifying the processes controlling the evolution of the major aerosol types, and in particular their physical, chemical, radiative, and cloud nucleating properties. Brenguier et al. (2000) focused on the CLOUDYCOLUMN subproject in trying to identify the indirect effect of pollution aerosol through its impact on a cloud layer. On some days (e.g. 18 and 19 July 1997), observations and model trajectories indicate advection of polluted continental air from Europe. European outbreaks of pollution contain aerosols principally from industrial by-products such as fossil fuel burning, but also contributions from farm land and wind-blown dust. Measurements were made on board the C-130 instrumented aircraft of the UK Met. Office. An overview of the instrumentation used during ACE-2 is given in Johnson et al. (2000), although it is worth describing briefly the pertinent instruments here. Accumulation mode aerosol size distributions (0.05-1.5 $\mu$ m radius) were measured with a Particle Measuring System (PMS) Passive Cavity Aerosol Spectrometer Probe (PCASP-100X). Cloud droplets and the coarse mode particles were measured with a PMS Forward Scattering Spectrometer Probe (FSSP). Given the measured aerosol chemistry and high relative humidity ( $\mathrm{RH})$ within the marine boundary layers (MBLs) studied here, it is safe to assume that the vast majority of particles were deliquesced and hence spherical. Therefore non-sphericity problems associated with the Particle Measuring System (PMS) probes that assume Mie scattering theory do not arise. However, the refractive indices associated with different aerosol types potentially cause sizing problems as the indices will differ from those of the calibration spheres. The aerosol spectra measured by the PCASP-100X are assumed to be dehydrated (Strapp et al., 1992).

Cloud liquid water content was measured with a JohnsonWilliams hot wire probe. Although this probe loses its collection efficiency for droplets $>30 \mu \mathrm{m}$, it is preferred to the method of integrating FSSP droplet spectra which potentially can introduce large errors (Gerber, 1996). These observations, together with the FSSP observations, gave a clear indication of the cloud depth.

In this analysis, the data (unless otherwise specified) have been averaged to $1 \mathrm{~Hz}$ which represents a horizontal distance of approximately $100 \mathrm{~m}$ and, during profiles, with a vertical resolution of typically $2.5 \mathrm{~m}$ within the MBL, and $5 \mathrm{~m}$ in the free troposphere (FT). The major ionic components of the aerosol particles were revealed by chemical analysis of bulk filter samples (Andreae et al., 2000). The sampling technique split the aerosol into a fine $(<0.75 \mu \mathrm{m})$ and a coarse fraction ( $>0.75 \mu \mathrm{m}$ radius). $\mathrm{SO}_{4}^{-2}$ was also analysed from filter samples.

The sea area between the Portuguese coast and the Canary Islands is strongly affected by the Azores anticyclone which provides subsidence in the FT and the creation of a stable inversion capping the MBL. Even within the continental outbreaks from Europe which often occur after the passage of a cold front in the mid-latitudes, enough moisture accumulates within the MBL over the few hours passage from the coast, that stratus, soon turning to stratocumulus, forms 
Table 1. Flight descriptions with the main Chemical and Microphysical model inputs.

\begin{tabular}{|c|c|c|}
\hline parameter & A562(polluted-1) & A560(polluted-2) \\
\hline Flight & A562 & A 560 \\
\hline Date & $19 / 07 / 97$ & $18 / 07 / 97$ \\
\hline Time (GMT) & 1200 & 0200 \\
\hline Cloud thickness (m) & 225 & 332 \\
\hline $\mathrm{CN}( \pm$ one standard deviation $)\left(\mathrm{cm}^{-3}\right)$ & $579 \pm 236$ & $1517 \pm 230$ \\
\hline$N_{A}( \pm$ one standard deviation $)\left(\mathrm{cm}^{-3}\right)$ & $315 \pm 118$ & $618 \pm 100$ \\
\hline$N_{d}( \pm$ one standard deviation $)\left(\mathrm{cm}^{-3}\right)$ & $112 \pm 27$ & $227 \pm 51$ \\
\hline $\begin{array}{l}k\left(r_{v o l}^{3} / r_{e}^{3}\right) \\
\text { (a factor related to } \\
\text { the mean volume radius and } \\
\text { the effective radius (see Eq. } 2 \text { ) }\end{array}$ & 0.74 & 0.71 \\
\hline $\begin{array}{l}\text { Surface wind speed }(10 \mathrm{~m} \text { height })\left(\mathrm{ms}^{-1}\right) \\
( \pm \text { one standard deviation) }\end{array}$ & $6.8 \pm 0.7$ & $6.8 \pm 0.6$ \\
\hline $\begin{array}{l}\mathrm{U}\left(\mathrm{ms}^{-1}\right) \\
\text { (updraught speed) }\end{array}$ & 0.39 & 0.68 \\
\hline $\mathrm{P}(\mathrm{hPa})$ & 911.5 & 926.4 \\
\hline $\mathrm{T}\left({ }^{\circ} \mathrm{C}\right)$ & 13.5 & 13.9 \\
\hline $\mathrm{RH}(\%)$ & 97.5 & 99.0 \\
\hline $\begin{array}{l}\mathrm{S}(\%) \\
\text { (supersaturation) }\end{array}$ & $<0.1$ & $0.12( \pm 0.04)$ \\
\hline \multicolumn{3}{|l|}{ Gas mixing ratio } \\
\hline $\mathrm{CO}_{2}(\mathrm{ppm})$ & 350.0 & 350.0 \\
\hline $\mathrm{NH}_{3}(\mathrm{ppb})$ & 0.3 & 0.3 \\
\hline $\mathrm{O}_{3}(\mathrm{ppb})$ & 30.0 & 45.0 \\
\hline $\mathrm{H}_{2} \mathrm{O}_{2}(\mathrm{ppb})$ & 1.0 & 1.0 \\
\hline $\mathrm{SO}_{2}(\mathrm{ppt})$ & 5.0 & 42.0 \\
\hline $\mathrm{HCl}(\mathrm{ppt})$ & $1.0 \mathrm{E}-5$ & $1.0 \mathrm{E}-5$ \\
\hline
\end{tabular}

readily. The MBL capped by stratocumulus was fairly deep (1-1.5 km) and nearly always decoupled, often with cumulus clouds developing below the base of the stratocumulus, and sometimes penetrating it. Cumulus-stratocumulus interaction can cause significant perturbations to the local cloud microphysics through an increase in liquid water content and hence changes to the droplet spectrum (Martin et al., 1994).

\subsection{Case studies}

Although both flights A562 and A560 are used here, flight A562 serves as the main case study for this paper. It was chosen because cumulus clouds were observed below the main stratocumulus clouds and on several occasion penetrated the main cloud deck. Some results from flight A560 were also used mainly to study the horizontal variability of the cloud optical properties along an extended horizontal flight path. This flight encountered unbroken cloudy regions (no drizzle was observed during this flight), and showed some variability in the droplet number concentrations. In addition, there were some variations in the cloud geometrical thickness along the horizontal: the overall thickness was $\sim 300 \mathrm{~m}$ and the vari- ability between the 4 runs were within $10 \%$. As a result this flight provided a good test case to study the horizontal variabilty of the optical thickness. No cumulus clouds were observed below the stratocumulus during flight A560 and, as explained below, we can infer that, the cloud was weakly decoupled.

Decoupling of a stratocumulus-topped MBL can occur through a number of mechanisms. Absorption of solar radiation near cloud top can create a vertical separation of heating and long-wave radiative cooling within the cloud that suppresses the turbulent motion to the sea surface. Thereby two circulations are established - one in the "cloud layer" and a second in the surface-mixed layer, the latter being driven by surface fluxes. Another method is the cooling due to evaporating drizzle drops falling below cloud base, stabilising the MBL and the resulting stratification can again create two largely independent circulations within the MBL. Surface driven thermals may become saturated so as to approximately follow the wet-adiabatic lapse rate, but their vertical motions will be damped if their buoyancy is negative near the stratocumulus cloud base. As a result, the stratocumulus cloud layer is decoupled, and cumuli are not able to 
Table 2. Dynamical input parameters for A562 case study cumulus model run.

\begin{tabular}{lc}
\hline Parameter & Value \\
\hline $\mathrm{P}(\mathrm{hPa})$ & 954.48 \\
$\mathrm{~T}\left({ }^{\circ} \mathrm{C}\right)$ & 16.46 \\
$\mathrm{RH}(\%)$ & 98.5 \\
$\mathrm{U}\left(\mathrm{ms}^{-1}\right)$ & 1.0 \\
\hline
\end{tabular}

penetrate the cloud layer. Lastly, if the cloud base is sufficiently high, dry surface-driven thermals may not be able to reach the cloud layer, as their buoyancy may become too negative in the upper parts. Given the high cloud base pressure for A560 from Table 1, this last scenario may be applicable too. Mechanistic details illustrating these processes are desribed in Stevens et al. (1998) and Bretherton and Wyant (1997). In addition, the surface-mixed layer can become conditionally unstable through the build-up of moisture and cumulus formation can provide sufficient lift to re-couple the surface layer with the stratocumulus layer aloft. The presence of cumulus cells with their bases below that of the stratocumulus is always a tell-tale sign of decoupling. Profiles of conserved variables such as equivalent potential temperature and total water content have been used to analyse the vertical structure of the MBL and to help assess the level of stratification. Decreases in the equivalent potential temperature of 1 to $5 \mathrm{~K}$ between the surface-mixed layer and the cloud layer indicate the range found during ACE-2 to correspond to weak to strongly decoupled MBLs, respectively.

\subsubsection{A562 (19 July 1997) - polluted-1 case study}

Flight A562 on 19 July 1997 was part of CLOUDYCOLUMN and was conducted in a polluted airmass. For this case, back trajectories show that the air mass travelled from France and the Iberian peninsula, although there was evidence that some of the air entrained into the MBL had come from the mid-North Atlantic having not encountered land for some time (Osborne et al., 2000). Indeed, A562 was conducted in the same airmass as A560 (about $30 \mathrm{~h}$ later), but the air within A562 was aged more than A560. This aging resulted in lower aerosol loadings, cloud droplet concentration and trace gas mixing ratios. The MBL was decoupled with cumulus clouds on occasion penetrating the stratocumulus (the cumulus bases were $\sim 460 \mathrm{~m}$ below the base of the stratocumulus). The aerosol had been heavily cloud-processed, more so than during A560. The presence of recent cloud processing of aerosol can be roughly ascertained through the shape of the aerosol spectrum across the accumulation mode (e.g. Kerminen and Wexler, 1995; Osborne et al., 2000; Dore et al., 2000).

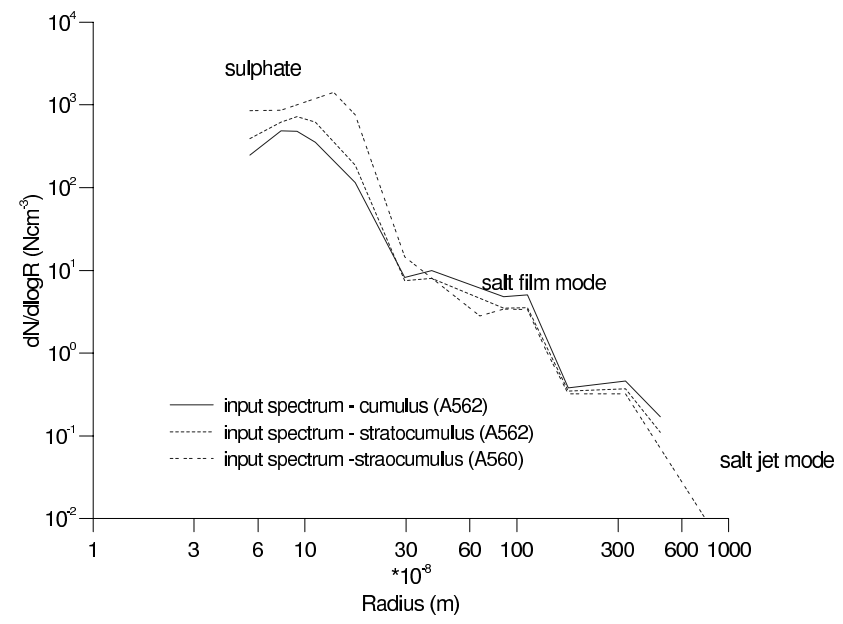

Fig. 1. Dry input aerosol spectra from C-130 observations. Note the higher accumulation mode aersol number concentration for the polluted-2 case (A560). Note also the presence of two distinct salt modes for all the cases

\subsubsection{A560 (18 July 1997) - polluted-2 case study}

Flight A560 on 18 July 1997 was part of a 3-flight Lagrangian experiment that is detailed in Osborne et al. (2000). The airmass was polluted from European sources and consequently the condensation nuclei $(C N)$, the aerosol number concentration $\left(N_{A}\right)$, and the cloud droplet number concentration $\left(N_{d}\right)$ values were the highest (see Table 1). Satellite imagery revealed that the air sampled had been over the ocean approximately $36 \mathrm{~h}$ and was likely to have been cloud processed for much of this period. A560 was a nighttime flight and, possibly as a result, the MBL was not significantly decoupled and therefore no cumulus clouds developed below the stratocumulus which maintained $100 \%$ cover throughout the flight.

In addition to the input parameters specified in Table 1 above, additional model runs required dynamical input parameters characterising the cumulus cloud present below the stratocumulus for the A562 case study. These are shown in the Table 2. The input updraught speed is a crucial input parameter, and this is based on the standard deviations of statistically significant number of data values for the vertical velocities observed during flights A562 and A560. The dry input aerosol spectra for initialising the model runs are shown in Fig. 1. Three distinct modes are clearly visible in these input spectra. The first represents the sulphate mode and covers much of the accumulation mode aerosol. In addition, there are two salt modes also clearly visible, corresponding to the fine film mode salt particles as well as the coarse jet mode. The existence of these salt modes are wind speed dependent (O'Dowd et al., 1999) and both modes are present in all the cases. Figure 1 also shows that the two A562 spectra are fairly similar, indicating that the aerosol was mixed 
fairly well throughout the depth of the MBL. From Fig. 1 we find that, as the extent of contamination increases, not only do the number concentrations progressively increase, but also the position of the maximum in the accumulation mode shifts towards larger sizes. For the polluted-1 (A562) case, it is placed at $0.092 \mu \mathrm{m}$ with a number concentration of $\sim 650 \mathrm{~cm}^{-3}$ and for the polluted-2 case (A560) the maximum shifts further to $0.137 \mu \mathrm{m}$ with a maximum number concentration of $\sim 1400 \mathrm{~cm}^{-3}$. From Table 1, we find that for the polluted-2 case, the $\mathrm{SO}_{2}$ concentration is more than 8 times higher - leading to the possibility of greater amounts of heterogeneously produced $\mathrm{SO}_{4}^{-2}$ causing this shift.

The similar positions of the film and jet sea salt modes in Fig. 1 when comparing the cumulus and stratocumulus input aerosol spectra indicate that significant mixing occurred between the sea surface and the base of the stratocumulus. Even though the MBL was decoupled, mixing would have taken place via cumulus re-coupling and diffusional mixing across the decoupled level. Also, the MBL may have been well-mixed during the previous night and became decoupled during daylight hours; therefore a signature of recent aerosol vertical mixing was still evident upon observation. Understandably, lower sea-salt particle concentrations are evident in the upper cloud layer as borne out by the smaller magnitude of the sea salt aerosol modes.

\section{Model description}

The model used is a Lagrangian parcel model with explicit micro-physics. The microphysical aspect utilises the dynamic growth equation (Pruppacher and Klett, 1997) to model the growth of aerosol solution droplets by condensation of water vapour on to a size-resolved droplet spectrum. Rather than being fixed, the boundaries of these size channels move as the solution droplets grow. The growth law includes curvature and solution effects, and is corrected for the breakdown of the continuum approximation close to the droplet surface (Pruppacher and Klett, 1997). Nonactivated solution droplets are especially concentrated, with ionic strengths often much greater than unity. Under these conditions, the solutions can no longer be treated as ideal, and non-ideal solution effects are accounted for in the calculation of water activity for each of the solution droplets. The water activity is then used to determine the supersaturation of the water vapour just above the droplet surface which in turn controls the rate of condensational growth of the droplets. Mass-transport limitations based on Schwartz (1986) have also been included. The aqueous phase chemical aspects of the model consists of (i) an equilibrium module, (ii) a kinetic reaction module, and (iii) the non-ideal behaviour correction module. The equilibrium module is used to calculate the amount of soluble gaseous species dissolved in the aerosol, and to apportion the aqueous aerosol species between the various associated as well as dissoci-

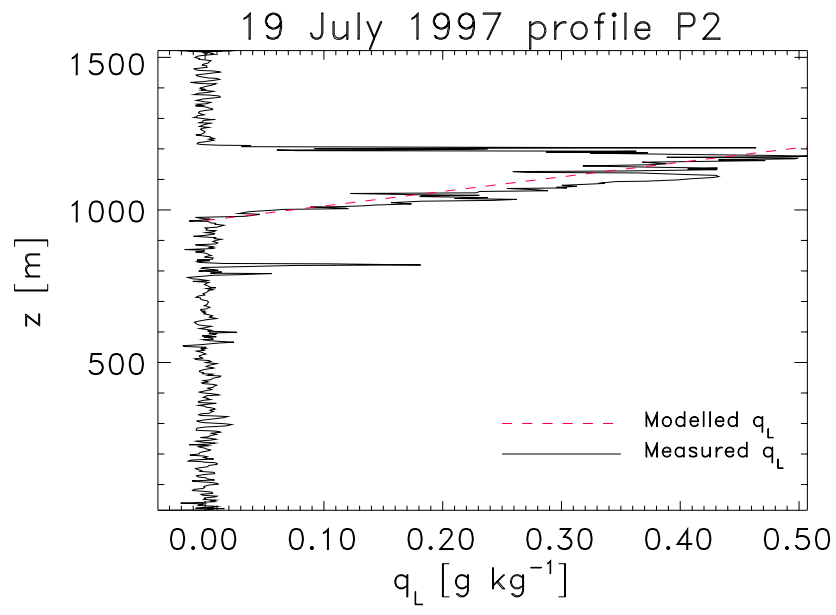

Fig. 2. Modelled and observed profile against height $(z)$ of LWC for the A562 case study. The modelled curve corresponds to the adiabatic LWC. Note that generally the LWC closely follows the adiabatic profile. The occasional super-adiabatic LWCs are a result of cumulus penetration

ated forms, which is achieved by solving the charge balance equation for each droplet. Thus, the model is ideally suited to study the growth and evolution of aerosol particles in the presence of air pollutants such as $\mathrm{SO}_{2}$. The aqueous activities of species equilibrating with the gas phase are calculated using Henry's law which also accounts for the temperature dependence. The non-ideal solution effects also affect aqueous phase chemical equilibria via Henry's law - the activity coefficients are functions of ionic strength, solution composition, as well as temperature. As the solution becomes more concentrated, these activity coefficients deviate from unity. The activity coefficients, and the water activity as used by the growth law are obtained from Pitzer (1991). The kinetic reaction module is used to compute the rate of heterogeneous sulphate production in the solution droplets and sulphate production is allowed to occur by $\mathrm{SO}_{2}$ oxidation using either dissolved $\mathrm{H}_{2} \mathrm{O}_{2}$ and/or $\mathrm{O}_{3}$ as the oxidant. The reaction rates and their temperature dependence are taken from Ayers and Larson (1990). This model was developed for clean marine environments using only sulphur chemistry and does not include nitrogen or other organic species. Droplet growth and chemistry takes place on both $\mathrm{NaCl}$ as well as $\left(\mathrm{NH}_{4}\right)_{2} \mathrm{SO}_{4}$ nuclei. Further details of the model can be found in O'Dowd et al. (1999).

\section{Microphysics and chemical processing}

First, we present the microphysical aspects of the model simulations. Figure 2 shows the adiabatic liquid water content (LWC) (labelled modelled $q_{L}$ ) compared with the C130 measurements for the A562 case study where cumulus clouds were observed to be present. For the A560 case study, 
Table 3. Modelled and Observed Fine mode concentration of ionic species.

\begin{tabular}{llll}
\hline Specie & $\begin{array}{l}\text { Polluted-1 (cumulus) } \\
\text { (A562 19 July 1997) } \\
(\mathrm{ppb})\end{array}$ & $\begin{array}{l}\text { Polluted-1 (stratocumulus) } \\
\text { (A562 19 July 1997) } \\
(\mathrm{ppb})\end{array}$ & $\begin{array}{l}\text { Polluted-2 } \\
\text { (A560 18 July 1997) } \\
(\mathrm{ppb})\end{array}$ \\
\hline $\mathrm{NH}^{+}$ & $0.391(0.65)$ & $0.84(0.65)$ & $1.1(1.326)$ \\
$\mathrm{SO}_{4}^{-2}$ & $0.194(0.2)$ & $0.42(0.2)$ & $0.55(1.27)$ \\
\hline
\end{tabular}

not shown here, the observations show that the LWC closely followed the adiabatic profile.

The apparent super-adiabatic parts observed in the polluted-1 A562 case in Fig. 2 arise due to the cumulus penetration from below. The cumuli had their bases below that of the stratocumulus and so were deeper clouds. The penetrations of the cumulus by the aircraft within the main stratocumulus layer do not necessarily imply penetration of their cores but most likely the relatively large area of mixing between the two, which will tend to elevate the LWC by small but significant amounts. The presence of cumulus clouds below the stratocumulus implies that the aerosol particles present in the cumulus are subjected to dynamicsdependent chemical processing over the two regimes. Differing updraught speeds and $\mathrm{RH}$ produce differences in spectral development causing unequal chemical processing over the two separate regimes - a cumulus processing regime and subsequently a stratocumulus processing regime. We have examined the differences in the chemical processing over the two regimes.

As indicated in Sect. 2.1, observations of the ionic species concentration were available for only the fine mode with aerosol radii less than $0.75 \mu \mathrm{m}$. This is also the most important mode covering the accumulation mode (with aerosol radii between $0.075-0.75 \mu \mathrm{m}$ ) which contains a large number concentration of active sulphate particles which participate in both the direct and indirect radiative forcings. These chemistry observations have enabled us to make detailed comparisons with model predictions. Note that cumulus clouds were observed to be present only for the A562 polluted-1 case study, where we have shown comparisons over the two regimes.

The heterogeneous processing of $\mathrm{SO}_{2}$ into $\mathrm{SO}_{4}^{-2}$ is very $\mathrm{pH}$ dependent: it is $\mathrm{O}_{3}$-led in the initial stages at high $\mathrm{pH}$, and $\mathrm{H}_{2} \mathrm{O}_{2}$-led at later stages when the $\mathrm{pH}$ has dropped below 5.5 (Seinfeld and Pandis, 1998; Lin et al., 1992). From an examination of model results (observed $\mathrm{pH}$ values were not available), we find that, for the $\left(\mathrm{NH}_{4}\right)_{2} \mathrm{SO}_{4}$ based droplets $(r<\sim 3 \mu \mathrm{m})$, the $\mathrm{pH}$ over all levels, including both the cloud layers, is always below 5 . It follows that the sulphate produced on these aerosol particles is exclusively $\mathrm{H}_{2} \mathrm{O}_{2}$ driven. However, for the larger sea salt particles $(r>\sim 3 \mu \mathrm{m})$ the $\mathrm{pH}$ is generally much higher, often reaching values close to 7 , and the sulphate production on these larger particles is pre- dominantly via the $\mathrm{O}_{3}$-driven pathway. We show results (Table 3) of the fine mode ionic concentrations for the A560 polluted-2 case study and the A562 polluted-1 case study with chemical processing over two regimes and the values within brackets correspond to observed values. Although, the observational data values were not demarcated as corresponding exclusively to either the cumulus or the stratocumulus regimes, a comparison with the model results gave a clear indication of the sampling regimes of the aircraft observations. This is made clear in the later discussions (see Sect. 5).

As expected, the amount of $\mathrm{SO}_{4}^{-2}$ in the fine mode is the highest for the polluted- 2 case. The increase in the $\mathrm{NH}_{4}^{+}$ ion concentration between the two polluted cases is due to the progressively higher ammonium sulphate loadings for the two cases, since the gas phase $\mathrm{NH}_{3}$ was maintained at the same level $(0.3 \mathrm{ppb})$ for both runs. Since only external mixtures were considered, the $\mathrm{NH}_{4}^{+} / \mathrm{SO}_{4}^{-2}$ ratios are exactly 2 as is expected. This point also serves to illustrate the overall robustness of the model runs, demonstrating that the runs are free from numerical biases. Likewise, in the coarse mode (not shown in the table), the modelled $\mathrm{Na}^{+} / \mathrm{Cl}^{-}$ratios are very nearly 1.0. The chlorine concentrations in the aerosol particles are mainly from the sea-salt since the amounts of gaseous $\mathrm{HCl}$ are very small and are the same in all cases.

Considering the various uncertainties arising out of internal mixing (in fact, measurements made on Tenerife during ACE-2 suggests that the majority of the aerosol was internally rather than externally mixed (Putaud et al., 2000)), entrainment effects, and the presence of many more contaminants than were considered by the model, the values agree reasonably well. In particular, we find that for the polluted1 case, the observed fine mode $\mathrm{SO}_{4}^{-2}$ concentration is much closer to the modelled value for the below-cloud cumulus regime, suggesting that the measured value must have included cloudy regions toward cloud base which contained parts of the cumulus cloud.

Possible discrepancies could have arisen due to many uncertainties involved with the measurements. The very high $\mathrm{NH}_{4}^{+} / \mathrm{SO}_{4}^{-2} \sim 3$ in the observations in the polluted-1 case is unrealistically high even if one recognises that the source regions of the aerosol over Europe may have had an abundance of $\mathrm{NH}_{3}$ and that ratios greater than 2 could be assigned to the presence of $\mathrm{HNO}_{3}$ which can bind some $\mathrm{NH}_{3}$ gas. 
Table 4. Modelled and observed optical properties.

\begin{tabular}{llll}
\hline Parameter & Polluted-1 (with cumulus) & polluted-1 & polluted-2 \\
\hline$N_{d}\left(\mathrm{~cm}^{-3}\right)$ & $112(112)$ & $192(112)$ & $290(227)$ \\
$r_{e}(\min )(\mu \mathrm{m})$ & $3.625(\sim 3.75)$ & $4.525(\sim 3.75)$ & $4.4(\sim 3.5)$ \\
$r_{e}(\max )(\mu \mathrm{m})$ & $11.3(10.0)$ & $10.8(10.0)$ & $9.45(9.5)$ \\
$\tau$ & $9.65(5.1-10.9)$ & $8.15(5.1-10.9)$ & $15.6(5.9-20.8)$ \\
\hline
\end{tabular}

Finally, observations showed that there were other anions, in particular $\mathrm{NO}_{3}^{-}$, not present in the model, which would have a propensity to suppress $\mathrm{SO}_{4}^{-2}$ production by buffering. Likewise, there were other cations including $\mathrm{Mg}^{+2}$ and $\mathrm{Ca}^{+2}$ which could affect the buffering action, in addition to the presence of other transition metals like Fe or Mn which favour $\mathrm{SO}_{4}^{-2}$ production (Seinfeld and Pandis, 1998).

The effect of extraneous pollutants such as $\mathrm{SO}_{2}$ can affect the Kohler chemistry and can also cause additional sulphate production on to the existing aerosol spectrum through cloud processing. These can potentially affect the cloud optical properties, which have been examined in the next section.

\section{Optical properties}

In this section, we discuss briefly the variations in droplet effective radii and optical depths. A general way of estimating the cloud optical depth $\tau$ is given by

$\tau=\frac{3}{2} \int \frac{q_{L}(z)}{\rho_{w} r_{e}(z)} d z$

where $\rho_{w}$ and $q_{L}$ are the liquid water density and the LWC, respectively, and the integration extends from the cloud base to the cloud top. The above equation for solar visible wavelengths is strictly valid only for a non-absorbing medium where the drop size is much bigger than the wavelength. $r_{e}$ is the droplet effective radius which is the ratio of the third to the second moment of the size spectrum and is related to the mean volume radius $r_{v o l}$ (and hence $q_{L}$ ):

$$
\frac{r_{v o l}^{3}}{r_{e}^{3}}=k
$$

where $k \sim 0.8$ for stratocumulus clouds. Martin et al. (1994) found some variation in the $k$ values between cloud types - they found that in continental air masses $k=0.67 \pm 0.07$ (one standard deviation) while in maritime air masses $k=0.80 \pm 0.07$. The mean volume radius is given by

$r_{v o l}=\left(\frac{3 q_{L}}{4 \pi N_{d} \rho_{w}}\right)^{1 / 3}$.

$q_{L}$ and $N_{d}$ are obtained from the model outputs and the optical depth is then calculated from Eqs. (1-3).
The observed $k$ values varied with height and were mainly within the stratocumulus which sometimes (A562 polluted-1 case) had cumulus penetration from below. We chose values from the top half of the stratocumulus layer where the value of $k$ is fairly constant with height (i.e. the droplet spectral shape is consistent) and they are 0.74 and 0.71 for the polluted-1 (without any cumulus effects) and polluted-2 cases respectively. We also simulated the effect of cumulus penetration in the A562 case study (polluted-1). For this latter case we used the cumulus dynamics to generate the LWC and, in the lower part of the cloud (up to $75 \mathrm{~m}$ ) we used a more marine-like value of $k(0.85)$. The average droplet number concentrations in the cumulus cloud were indeed marinelike with a number concentration of $112 \mathrm{~cm}^{-3}$, both in the model as well as the observations. In contrast, for the main stratocumulus cloud deck the modelled droplet number concentration was much higher $\left(\sim 192 \mathrm{~cm}^{-3}\right)$. This trend in the droplet number concentration also points to the fact that the observed $N_{d}$ values are actually representative of the lower end of the stratocumulus cloud containing the cumulus cloud which the aircraft sampled. Table 4 shows the modelled values along with the observations (bracketed quantities).

We find that, with increasing levels of pollution, there is a consistent decrease in the droplet effective radii in the observations as well as in the model runs when we consider the polluted- 2 case and the polluted- 1 case with only the main stratocumulus deck. Although we have shown the maximum and the minimum values of the effective radii in each case, the full range of values also corroborate this trend and in addition, as would be expected, the effective radii increase with height since the LWCs increase adiabatically with height. (The maximum values are close to the cloud top while the minimum values are towards the cloud base). When one compares model results with the observations, it is clear that the observed values also have significant contributions from regions within the cumulus cloud. It follows that the aircraft flew through cloudy regions within cumulus penetrations as it sampled the main stratocumulus deck. The minimum values of the effective radii clearly correspond to values when the aircraft, while sampling the stratocumulus base, also sampled cloudy regions well within the cumulus cloud tops that penetrated the stratocumulus. Thus, the effect of the cumulus penetration are the most pronounced near the base of the stratocumulus (corresponding to the minimum values 
Table 5. Horizontal variability of optical properties for the polluted2 (A560) case study.

\begin{tabular}{lcccc}
\hline Parameter & Run 1 & Run 2 & Run 3 & Run 4 \\
\hline$N_{d}\left(\mathrm{~cm}^{-3}\right)$ & 170 & 140 & 159 & 116 \\
$r_{e}(\min )(\mu \mathrm{m})$ & 3.13 & 4.06 & 2.89 & 3.22 \\
$r_{e}(\max )(\mu \mathrm{m})$ & 8.48 & 9.04 & 8.66 & 9.48 \\
$\tau$ & 9.6 & 9.02 & 9.4 & 7.62 \\
\hline
\end{tabular}

of the effective radii). As a result, the difference between the maximum values in the effective radii between the two cases (with and without cumulus penetration) is insignificant. The observed values of the maximum effective radii correspond to regions where the aircraft flew through the stratocumulus top. The stratocumulus tops were free from cumulus incursions, and over these regions the model effectively captured the maximum values of the effective radii even without including cumulus penetration effects.

The modelled values, along with the observations, suggest that, during ACE-2 and in general, more polluted stratocumulus clouds have higher droplet number concentrations, reduced effective radii and higher optical depths. Polluted clouds with greatly reduced droplet sizes have reduced collision efficiencies as a result of which drizzle formation is suppressed and the cloud is geometrically thicker and longer lasting. All these factors can combine together to yield higher optical depths for polluted clouds and further exacerbate the radiative cooling effect associated with the indirect forcing effect of aerosols.

Although the modelled values of the effective radii as well as the optical depths are in good agreement with the observations, we should note that the model values are based on a single vertical profile - all horizontal variations are ignored, while the aircraft measurements span a whole range of horizontal variations. Recent studies by Los and Duynkerke (2000) show evidence of horizontal inhomogeneity in the ASTEX stratocumulus clouds. In our study, in order to account for this variability, we have conducted a further 4 sensitivity tests for the A560 polluted- 2 case. As explained earlier, we chose this particular case because it showed the largest number concentration variability along the horizontal among all the cases considered here. Each model run is based on an aerosol distribution which is an average over a 7 min run, covering a horizontal distance of about $42 \mathrm{~km}$. In addition to the variabilities associated with the aerosol spectrum, we also considered the variations in the updraught speed. The pressure, temperature and the $\mathrm{RH}$ at the cloud base were not very different for the 4 runs. In order to estimate realistically the horizontal variability of the microphysical properties, it was essential that we include mixing induced by entrainment effects. We used an entraining parcel model developed by Mason and Jonas (1974) where mixing of entrained air is de- termined by the vertical velocity and radius of the parcel. The rate of mass dilution due to entrainment is proportional to the vertical velocity $U$ and inversely proportional to the radius $R$ of the parcel - i.e. $0.6 U / R$. The constant of proportionality is based on observations and further details of the model are described in Mason and Jonas (1974). These sectional runs aimed to establish how the optical properties could vary in the horizontal and a summary of the results are shown in Table 5 .

From Table 5 we observe a modest degree of variability in the sectional runs with entrainment effects. The optical depth in Run 4 is about $26 \%$ lower than that in Run 1 , and overall, the Run 4 optical depth is approximately $20 \%$ lower than the other 3 runs. Some measure of variability was also observed for the droplet number concentration $N_{d}$. Although the overall cloud geometric thickness across the horizontal was $\sim 300 \mathrm{~m}$, a $10 \%$ variability in the cloud thickness was also observed for the four runs. In addition, there were some differences in the input aerosol spectrum for the four runs. The aerosol data for the four separate runs contained 30 bins each. This ranged from the smallest bin size of $0.055 \mu \mathrm{m}$ to the largest bin with a size of $22.75 \mu \mathrm{m}$. The accumulation mode aerosol size distributions were measured with a PCASP-100X probe and the coarse mode with FSSP. Although the peak number concentration were located at $0.137 \mu \mathrm{m}$ radius, i.e. centred around the accumulation mode for all the 4 runs, the number concentrations showed some variability, particularly within the first 3 runs - the peak concentrations were $1574,1188,1265$, and $1574 \mathrm{~cm}^{-3}$ respectively. Since the number concentrations in the coarse mode were small, the variability in the coarse mode concentrations were much less apparent - for example for a bin size of $1.75 \mu \mathrm{m}$ the number concentrations were $0.3,0.34,0.285$, and $0.33 \mathrm{~cm}^{-3}$ respectively.

We shall now specifically explore how the dynamics could have affected differences in the resultantant drop size distribution in addition to the differences in the dry aerosol input spectra in the four runs. The key dynamical factor that caused the variability can be attributed to the differences in the updraught speed. It is important to note that although the peak number concentration for Run 1 and Run 4 were the same, the average updraught speeds were quite different $\left(0.66\right.$ and $0.58 \mathrm{~ms}^{-1}$, respectively). The other thermodynamic factors, i.e. the $\mathrm{RH}$, the temperature and pressure at the cloud were roughly the same for the 4 runs ( $~ 99 \%$, $12.5^{\circ} \mathrm{C}$ and $\left.915 \mathrm{hPa}\right)$. When entrainment effects are included, the variability in the updraught speeds caused a greater variability in the overall microphysical development because, in the simple model used, the mass dilution due to entrainment is directly proportional to the updraught speed (Mason and Jonas, 1974) which were $0.66,0.71,0.61$ and $0.58 \mathrm{~ms}^{-1}$ for Runs 1-4 respectively. Based on all these above facts, it is abundantly clear that differences in the updraught speeds were the greatest contributing factors for the microphysical variability within the four sectional runs. However, it should 
be pointed out although the extent of variability in the microphysical properties depended on the entrainment rate, for the present case study, even entrainment-induced variability were not very large - for most parts of the cloud the overall observed LWC were adiabatic.

\section{Spectral development}

We shall now examine the droplet spectra with and without cumulus penetration by concentrating on the A562 case study which clearly indicated the presence of cumulus, and compare it with the observed spectrum. Figure 3 shows the observed and the modelled cloud droplet spectrum at $179 \mathrm{~m}$ above the cloud base (approximately midway between the stratocumulus base and the top). This spectrum was grown from a measured dry aerosol spectrum (see Fig. 1) using measured dynamical inputs.

It is observed that, when cumulus effects are excluded, there is agreement between the observed and the modelled spectra only at the largest sizes. The pronounced peak in the observed spectrum centred around $10 \mu \mathrm{m}$ is not correctly captured by the model run - the modelled peak is located at a much smaller size range. The ascending air parcel encountered lower RH as it moved up from the cumulus cloud to the stratocumulus. This may have a small drying effect in addition to cloud top entrainment of FT air. However, it is quite clear that some other mechanisms were operative. The most likely mechanism is the expected coupling between the cumulus cloud below with the main stratocumulus deck above. As discussed earlier in Sect. 2, a close examination of the MBL during A562 indeed revealed that, on several occasions, cumulus clouds penetrated the base of the main stratocumulus cloud. Thus, the observed droplet spectra are likely to represent some degree of mixing between the stratocumulus and the cumulus. These discussions imply that it is very important to allow for the incursion and mixing of parcels of cloudy air having typical cumulus droplet size spectra into layers of stratocumulus. This mixing was achieved in two stages in the model runs. First, a dry aerosol spectrum was used and the model was run with dynamical parameters corresponding to the cumulus cloud. Then, the evolving aerosol spectrum was tracked until it reached the stratocumulus base $(\sim 911.5 \mathrm{hPa})$. Finally, this evolved spectrum was used to configure a further model run, but this time with stratocumulus dynamics. Figure 3 also shows this resultant spectrum. It is clear that the comparison between the observed and the modelled spectra is markedly better, and importantly, the peak in the distribution pattern around $10 \mu \mathrm{m}$ is now well captured.

It is important to point out that the model does not include collision-coalescence effects. However, in reality, droplets with radii $>30 \mu \mathrm{m}$ have appreciable fall velocities. For example, drops with 40 and $100 \mu \mathrm{m}$ radii have fall velocities of the order of $18 \mathrm{~cm} \mathrm{~s}^{-1}$ and $72 \mathrm{~cm} \mathrm{~s}^{-1}$ respectively. Since the

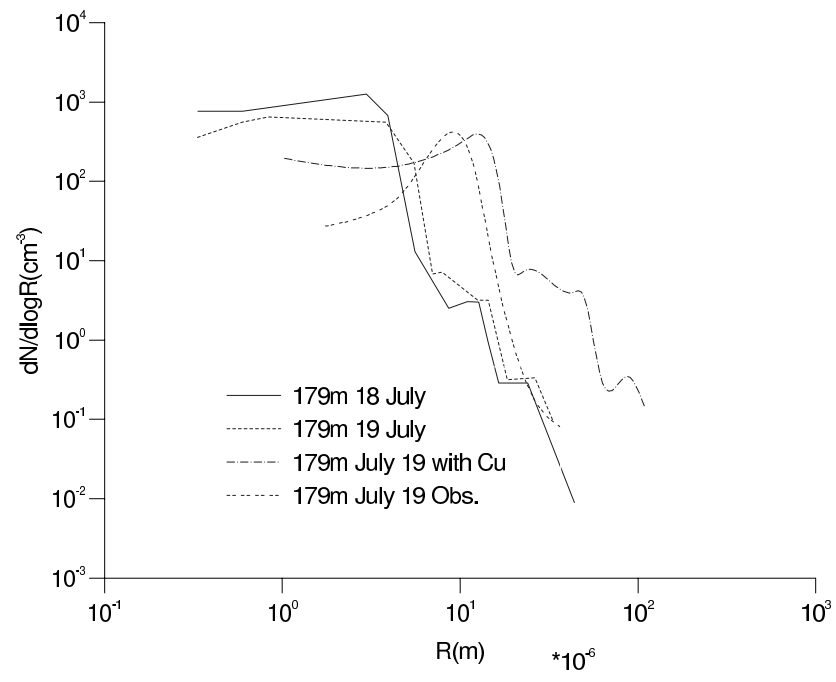

Fig. 3. Modelled spectra with and without cumulus penetration compared with observations. Note that the curve labelled $179 \mathrm{~m} 19$ July with $\mathrm{Cu}$ (corresponding to the case with cumulus incursions) agrees more favourably with the observed curve than the standard case without cumulus incursions (labelled $179 \mathrm{~m} 19$ July)

cloud thickness is about $225 \mathrm{~m}$, drops with these radii would fall out of the cloud in 20 and $5 \mathrm{~min}$, respectively. For this reason, in Fig. 3, the large end tail of the model (curve 3 marked 179 m July 19 with $\mathrm{Cu}$ ) is considerably larger than the observations (curve 4).

The small over-prediction in the modelled droplet radii can also be attributed to chemical effects. The model assumes a pure externally-mixed aerosol spectrum. However, some of these aerosol particles must have been internally mixed with less hygroscopic carbonaceous particles. This mixture would have an inhibiting effect on the aerosol growth. Sensitivity tests with variable soluble mass fractions can enable one to obtain a quantitative estimate on the variability associated with chemical effects. For our purposes, however, it is reasonable to believe that entrainment and mixing effects dominate over chemical effects. Entrainment of dry FT air at the cloud top would have a great propensity to evaporate the smallest of the droplets. We shall examine these issues through a bin-resolved large eddy model in a later study.

Finally, we have also studied the spectral evolution for the A562 case study from the point of view of chemical processing. We achieved this by also examining the droplet spectrum about $24 \mathrm{~h}$ earlier i.e. the spectrum on the 18 July (A560 polluted-2 case) in order to study how aging and chemical processing could have affected the spectral evolution. On 18 July, the aerosol particles encountered comparatively higher levels of $\mathrm{SO}_{2}(42 \mathrm{ppt})$ and $\mathrm{O}_{3}(45 \mathrm{ppb})$. The overall $\mathrm{H}_{2} \mathrm{O}_{2}$ concentrations did not show much variations and were taken to be the same on both days covering our case studies. Model results showed that much of the $\mathrm{pH}$ levels for the ammonium sulphate based droplets ranged from 4 to 6 indicating that 
sulphate production was effected predominantly by $\mathrm{H}_{2} \mathrm{O}_{2}$ (and to some extent, by $\mathrm{O}_{3}$ when the $\mathrm{pH}$ was above 5.5) causing a very substantial increase in the total amount of sulphate.

On the following day (19 July, polluted-1), measurements indicated an increase in the number concentration of the coarse mode sea-salt based aerosol particles (see the second (stratocumulus A562) and the third (stratocumulus A560) curves in Fig. 1). Sulphate production via the $\mathrm{O}_{3}$-led pathway increased on droplets grown from these particles as compared to 18 July. In-cloud drizzling within the main stratocumulus cloud deck was not observed on either of these days, but led to further mixing and aging of the 18 July aerosol spectrum. These features are immediately recognisable when we compare the droplet spectra in the cloud for the two days (see Fig. 3). The higher levels of sulphate production causes a peak in the number density for droplets that grew from ammonium sulphate. This feature smooths out on the following day due to mixing and aging processes and also due to reduced sulphate production on these smaller aerosol particles caused by a significant fall in the $\mathrm{SO}_{2}$ level from $42 \mathrm{ppt}$ to $5 \mathrm{ppt}$ (see the first two curves of Fig. 3 corresponding to a level within the main stratocumulus deck only, with only stratocumulus type aerosol processing). However, sulphate production on the larger sea-salt based droplets increased on 19 July causing a distinct shift in the spectra towards larger sizes. Since the effect of aging and mixing on a time span of a day have less influence on the larger particles, the spectral shape is preserved.

These subtle chemical effects leave their signature on the optical properties too. Under the most polluted conditions (18 July) when the $\mathrm{SO}_{2}$ level was a maximum, the optical thickness was the highest with the smallest droplet effective radius. The following day (19 July) was less polluted with lower $\mathrm{SO}_{2}$ concentration and the optical depth and the effective radii were lower (see Table 4).

\section{Concluding remarks}

The analysis presented in this paper (which includes model simulations as well as observations) shows that, when cumulus clouds penetrate the bases of stratocumulus clouds, as was the case during ACE-2, the chemical, microphysical and optical properties are perturbed by the presence of the cumulus. Any model studies aiming to compare these cloud properties with observations should account for this cumulusstratocumulus coupling in order to have a meaningful comparison. For the ACE-2 case studies considered in this paper, our analysis revealed that the observed chemical, microphysical and optical parameters from the C-130 aircraft observations had significant contributions from regions within the cumulus cloud in addition to contributions from the main deck. The amount of fine mode ionic species (Table 3), the average droplet number concentrations, the effective radii and the optical depths (Table 4) during the flight A562 (when cumulus clouds interacted with the main stratocumulus) were estimated. The model runs which included this effect yielded microphysical and optical properties which compared more favourably with the observations than the runs which did not. In particular, the minimum values of the effective radii were greatly influenced by the cumulus incursions and clearly corresponded to situations when the aircraft sampled cloudy regions well within the cumulus cloud tops that penetrated the stratocumulus base. The observed range of the optical depth variability is also indicative of sampled cloudy air which included regions of the cumulus along with the main stratocumulus deck. It is also observed that when cumulus effects are excluded, there is some agreement between the observed and the modelled spectra only at the largest sizes (radii in excess of $50 \mu \mathrm{m}$ ). The pronounced peak in the observed spectrum centred around $10 \mu \mathrm{m}$ is not correctly captured by the model run - the modelled peak is located at a smaller size range. When the initial dry aerosol spectrum was grown first with cumulus dynamics and then the evolved spectrum at the stratocumulus base was subjected to a further cycle of cloud processing with a stratocumulus dynamics, the resulting spectrum agreed favourably with the observations.

During ACE-2, observational evidence suggests that aerosol particle composition was sometimes more complicated than the model assumptions. For example, in this study we have modelled aerosol spectra comprising only ammonium sulphate and sea salt. The ACE- 2 observations have shown that, although the aerosol particles were predominantly composed of these two components, some measure of internal mixing with other components such as black carbon, dust, organic aerosol and nitrates, was also present. Although a daunting task, we hope to incorporate internally mixed aerosol particles as well as some other gases such as nitric acid in future model runs. It is expected that the effect of internal mixing will affect the droplet activation process both in the cumulus as well as the stratocumulus regimes.

Edited by: U. Lohmann

\section{References}

Andreae, M.-O., Elbert, W., Gabriel, R., Johnson, D. W., Osborne, S., and Wood, R.: Soluble ion chemistry of the atmospheric aerosol and $\mathrm{SO}_{2}$ concentration over the eastern North Atlantic during ACE-2, Tellus, 52B, 1066-1087, 2000.

Ayers, G. P. and Larson, T. V.: Numerical study of droplet size dependent chemistry in oceanic, wintertime stratus cloud at southern mid-latitudes, J. Atmos. Chem., 11, 143-167, 1990.

Brenguier, J.-L., Fouquart, Y., Johnson, D. W., Parol, F., Pawlowska, H., Schuller, L., Schroder, F., and Snider, J.: An overview of the ACE-2 CLOUDYCOLUMN closure experiment, Tellus, 52B, 815-827, 2000.

Bretherton, C. S. and Wyant, M. C.: Moisture transport, lowertropospheric stability, and decoupling of cloud-topped boundary layers, J. Atmos. Sci., 54, 148-167, 1997.

Dore, A. J., Johnson, D. W., Choularton, T. W., Osborne, S. R., and Andreae, M. O.: Evolution of boundary layer aerosol particles 
due to in-cloud chemical reactions during the second Lagrangian experiment of ACE-2, Tellus, 52B, 452-463,2000.

Gerber, H.: Microphysics of marine stratocumulus clouds with two drizzle modes, J. Atmos. Sci., 53, 1649-1662, 1996.

Jonas, P. R.: Turbulence and cloud microphysics, Atmos. Res., 40, 283-306, 1996.

Johnson, D. W., Osborne, S. R., Wood, R., Suhre, K., Andreae, M. O., Johnson, R., Businger, S., Quinn, P. K., Bates, T., Durkee, P., Jonson, H., Russell, L. M., Noone, K., Glantz, P., Bandy, B., O'Dowd, C., Rapsomanikis, S., and Rudolph, J.: An overview of the Lagrangian experiments undertaken during the North Atlantic regional Aerosol Characterisation Experiment (ACE-2), Tellus, 52B, 290-320, 2000.

Kerminen, V. and Wexler, A. S.: Growth laws for atmospheric aerosol particles: an examination of the bimodality of the accumulation mode, Atmos. Environ., 29, 3263-3275, 1995.

Lin, X., Chameides, W. L., Kiang, C. S., Stelson, A. W., and Berresheim, H.: A model study of formation of cloud condensation nuclei in remote marine areas, J. Geophys. Res., 97, 18 161$18171,1992$.

Los, A. and Duynkerke, P. G.: Microphysical and radiative properties of inhomogeneous stratocumulus: Observations and model simulations, Quart. J. R. Met. Soc., 126, 3287-3307, 2000.

Martin, G. M., Johnson, D. W., Rogers, D. P., Jonas, P. R., Minnis, P., and Hegg, D.: Observations of the interaction between cumulus clouds and warm stratocumulus clouds in the marine boundary layer during ASTEX, J. Atmos. Sci., 52, 2902-2922, 1995.

Martin, G. M., Johnson, D. W., and Spice, A.: The measurement and parametrization of effective radius of droplets in warm stratocumulus clouds, J. Atmos. Sci., 51, 1822-1842, 1994.

Mason, B. J. and Jonas, P. R.: The evolution of droplet spectra and large droplets by condensation in cumulus clouds, Quart. J. R. Met. Soc., 100, 23-38, 1974.

O'Dowd, C., Lowe, J. A., and Smith, M. H.: Observations and modelling of aerosol growth in marine stratocumulus-case study, Atmos. Environ., 33, 3053-3062, 1999.
Osborne, S. R., Johnson, D. W., Wood, R., Bandy, B. J., Andreae, M. O., O’Dowd, C., Glantz, P., Noone, K., Gerbig, C., Rudolph, J., Bates, T., and Quinn, P.: Evolution of the aerosol, cloud and boundary-layer dynamic and thermodynamic characteristics during the 2nd Lagrangian experiment of ACE-2, Tellus, 52B, 375400, 2000.

Pitzer, K. S.: Activity Coefficients in Electrolyte Solutions, CRC Press, Ann Arbor, 1991.

Pruppacher, H. R. and Klett, J. D.: Microphysics of Clouds and Precipitation, Kluwer Academic, Dordredcht, 1997.

Putaud, J. P., Van Dingenen, R., Mangoni, M., Virkkula, A., Raes, F., Maring, H., Prospero, J. M., Swietlicki, E., Berg, O. H., Hillamo, R., and Makela, T.: Chemical mass closure and origin assessment of the submicron aerosol in the marine boundary layer and the free troposphere at Tenerife during ACE-2, Tellus, 52B, 141-168, 2000.

Raes, F., Bates, T., Verger, G., McGovern, F., and Van Liedekerke. M.: The second aerosol characterisation experiment (ACE-2): general context and main results, Tellus, 52B, 111-126, 2000.

Schwartz, S. E.: Mass-transport considerations pertinent to aqueous phase reactions of gases in liquid-water clouds, in: Chemistry of Multiphase Atmospheric Systems, edited by: Jaeschke, W. NATO ASI ser., Springer New York. 1986.

Seinfeld, J. H. and Pandis, S. N.: Atmospheric Chemistry and Physics: From Air Pollution to Climate Change, John Wiley, New York, 1998.

Stevens, B., Cotton, W. R., Feingold, G., and Moeng, C. H.: Large-eddy simulations of strongly precipitating, shallow, stratocumulus-topped boundary layers, J. Atmos. Sci., 55, 36163638, 1998.

Strapp, J. W., Leaitch, W. R., and Liu, P. S. K.: Hydrated and dried aerosol distribution measurements from the Particle Measuring System FSSP-300 probe and the deiced PCASP-100X probe, J. Atmos. Oceanic Tech., 548-555, 1992. 